\title{
Optimasi Nilai Bobot Algoritma Backpropagation Neural Network Dengan Algoritma Genetika
}

\author{
Moh. Dasuki ${ }^{1}$ \\ ${ }^{1}$ Jurusan Teknik Informatika, Fakultas Teknik, Universitas Muhammadiyah Jember, \\ Email: ${ }^{1}$ moh.dasuki22@unmuhiember.ac.id
}

(naskah masuk: 10 Juni 2021, maskah diterima untuk diterbitkan: 15 Juni 2021)

\begin{abstract}
ABSTRAK
Backprogation Neural Network (BPNN) merupakan salah satu metode peramalan yang sudah banyak dilakukan kemampuan Artificial Neural Network dalam melakukan suatu pembelajaran terbukti mempunyai kinerja yang cukup baik, namun Backpropagation memiliki dua kelemahan utama yaitu kecepatan convergence yang buruk dan tidak stabil, hal ini disebabkan karena resiko terjebaknya pada lokal minimum. Dua kelemahan itu dipengaruhi bobot awal yang dipilih secara random. Algoritma Genetika akan digunakan untuk menentukan bobot serta bias awal terhadap parameter Backpropagation sehingga bisa mendapatkan kemampuan belajar yang baik. Hasil yang diperoleh dari experiment yang sudah dilakukan menggunakan Backprogation Neural Network menghasilkan Root Mean Sequare Error 0,120 setelah dioptimasi menggunakan Algoritma Genetika menghasilkan nilai Root Mean Sequare Error 0.115. Kesimpulan dari penelitian ini penentuan bobot awal pada Backprogation Neural Network mempengaruhi model yang dihasilkan sehingga dapat meningkatkan kinerja Backprogation Neural Network lebih baik.
\end{abstract}

Kata kunci: Backprogation, Neural Network, Genetic Algorithm, Optimization, Prediction

\begin{abstract}
Backpropagation Neural Network (BPNN) has two main weaknesses, namely poor and unstable convergence speed, this is due to the risk of being trapped at a local minimum. The two drawbacks are affected by a randomly selected start. Genetic Algorithm will be used to determine the initial weight and bias of the Backpropagation parameter so that it can get good learning abilities. The results obtained from experiments that have been carried out using the Backprogation Neural Network produce a Root Mean Sequare Error 0.120 after being optimized using a Genetic Algorithm to produce a Root Mean Sequare Error value of 0.115. The conclusion of this study is that the initial weight of the Backprogation Neural Network affects the resulting model so that it can improve the performance of the Neural Network better.
\end{abstract}

Keywords: Backprogation, Neural Network, Genetic Algorithm, Optimization, Prediction 


\section{PENDAHULUAN}

Artificial Neural Network merupakan salah satu metode peramalan yang sudah banyak dilakukan kemampuan Artificial Neural Network dalam melakukan suatu pembelajaran terbukti mempunyai kinerja yang cukup baik, salah satu jenis metode pembelajaran Artificial Neural Network adalah Backpropagation. Backpropagation melatih jaringan untuk mendapatkan keseimbangan antara kemampuan jaringan mengenal pola yang digunakan selama pelatihan serta kemampuan jaringan untuk memberikan respon yang benar terhadap pola masukan yang serupa dengan pola yang dipakai selama pelatihan.

Menurut (Habib 2013) Backpropagation memiliki kemampuan untuk mengatasi permasalahan pelatihan klasifikasi dengan skala data yang luas, hal ini membuat Backpropagation menjadi algoritma pelatihan yang terkenal. Namun menurut (Nawi, Khan, and Rehman 2013) Backpropagation memiliki dua kelemahan utama yaitu kecepatan convergence yang buruk dan tidak stabil, hal ini disebabkan karena resiko terjebaknya pada lokal minimum. Dua kelemahan itu dipengaruhi bobot awal yang dipilih secara random. Ditambahkan juga oleh (Burse, Manoria, and Kirar 2011) dalam menghitung perubahan bobot algoritma Backpropagation dapat menyebabkan masalah lokal minimum.

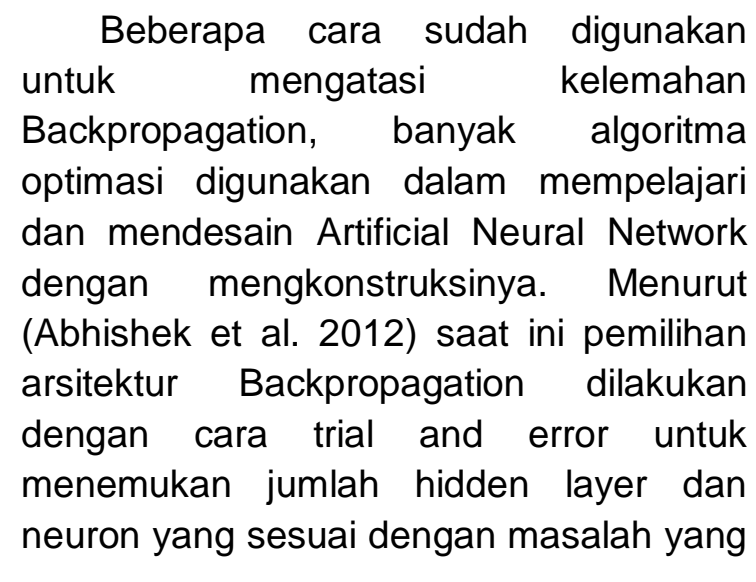

ada. Penelitian (Cui and Curry 2005) membandingkan optimasi Particle Swarm Optimization dan Algoritma Genetika, dimana Algoritma Genetika digunakan untuk menyediakan pola bobot yang baik dalam meningkatkan pembelajaran dari Backpropagation, dan Particle Swarm Optimization digunakan untuk mengamati kecepatan convergence dan akurasi klasifikasi dari Feedforward Neural Network. Performa belajar Backpropagation bergantung pada arsitektur, fungsi aktivasi dan bobot awal, maka kombinasi arsitektur dan bobot awal yang baik akan menentukan hasil dari sebuah neuron yang akan dirambatkan pada jaringan diatasnya yang kemudian akan menjadi keluaran (Nikelshpur and Tappert 2013).

Algoritma Genetika akan digunakan untuk menentukan bobot serta bias awal terhadap parameter Backpropagation sehingga bisa mendapatkan kemampuan belajar yang baik. Menurut (Sexton and Sikander 2001) Algoritma Genetika memulai dengan multiple random point sebagai inisial populasi ketika mencari solusi. Setiap solusi kemudian dievaluasi berdasarkan fungsi objektif, setelah selesai solusi tersebut kemudian dipilih untuk generasi selanjutnya berdasarkan fitness mereka. Bahkan (Ding, Su, and Yu 2011) menggunakan Algoritma Genetika untuk menghindari stuck pada lokal minimum, dan memberikan hasil yang lebih stabil dengan cara menentukan bobot jaringan yang bisa beradaptasi setiap iterasi terhadap model arsitektur yang telah ditentukan secara manual.

\section{METODOLOGI PENELITIAN}

Berikut metodologi penelitian yang digunakan.

\subsection{Metode Pengumpulan Data}

p-ISSN : 2502-5724; e-ISSN : 2541-5735 
Data set yang digunakan adalah data time series.

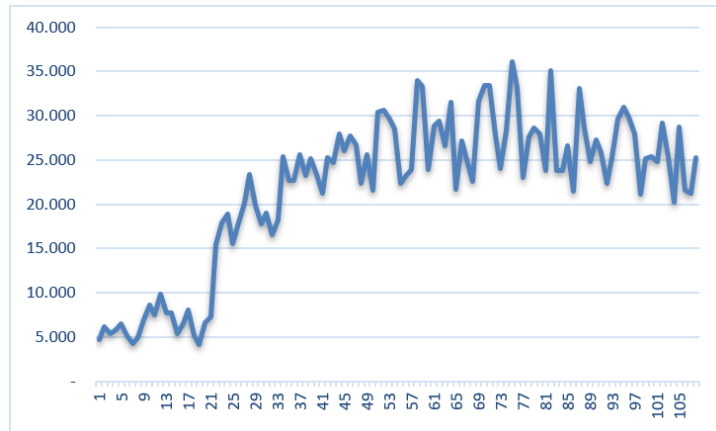

Gambar 2.1: Data Time Series

\subsection{Metode Pengolahan Data}

Pengolahan data atau normalisasi, perlu dilakukan untuk memberikan pengaruh kepada data yang lebih efisien, redundansi (pengulangan), dan bebas anomaly. Perhitungan normalisasi data dapat menggunakan persamaan (1). (Siregar 2017).

$$
x^{\prime}=\frac{0.8(x-\min \text { value })}{\max \text { value }-\min \text { value }}+0.1
$$

\subsection{Perancangan Struktur Dan Parameter}

Setelah data dinormalisasi selanjutnya adalah mengubah data tersebut menjadi data yang siap diolah dengan menentukan parameterparamenter Neural Network meliputi training cycle, learning rate, momentum, input layer, hidden layer dan output yang selanjutnya dilanjutkan untuk proses pembelajaran.

\subsection{Pembagian Data}

Data dibagi menjadi dua, data training dan data testing menurut (Wanto 2018) umumnya komposisi data pelatihan dan pengujian yang sering digunakan oleh peneliti adalah sebagai berikut.

- $80 \%$ data pelatihan dan $20 \%$ data pengujian.

- $70 \%$ data pelatihan dan $30 \%$ data pengujian.

p-ISSN : 2502-5724; e-ISSN : 2541-5735
- 23 data pelatihan dan 13 data pengujian.

- $50 \%$ data pelatihan dan $50 \%$ data pengujian.

- $60 \%$ data pelatihan dan $40 \%$ data pengujian.

\subsection{Experimen Dan Pengujian Model}

Untuk mengetahui hasil dari Artificial Neural Network dengan Algoritma Genetika terhadap model yang di peroleh diperlukan pengaturan parameterparameter yang tepat, agar mendapatkan hasil yang lebih baik. Langkah-langkah experimen menggunakan Artificial Neural Network sebagai berikut:

\section{Langkah 0}

Inisialisasi bobot (ambil nilai random yang cukup kecil)

\section{Langkah 1}

Selama kondisi berhenti bernilai salah, kerjakan:

\section{Tahap Forward Propagation Langkah 1}

Setiap unit input (xi, $i=1,2,3, \ldots, n)$ menerima sinyal xi dan meneruskan sinyal tersebut ke semua unit pada lapisan tesembunyi.

\section{Langkah 2}

Setiap unit tersembunyi ( $z i, j=1,2,3, \ldots, p)$ menjumlahkan bobot sinyal input.

Dan menerapkan fungsi aktivasi untuk menghitung sinyal output-nya.

\section{Langkah 3}

Setiap unit output (yk, $k=1,2,3, \ldots, m)$ menjumlahkan bobot sinyal input.

Dan menerapkan fungsi aktivasi untuk menghitung sinyal output layer.

\section{Tahap Backpropagation \\ Langkah 1}

Setiap unit outpul layer ( $\mathrm{yk}, \mathrm{k}=1,2,3, \ldots, \mathrm{m})$ menerima pola target yang sesuai dengan pola input pelatihan, kemudian hitung nilai eror-nya. 
Kemudian hitung koreksi bobot dan biasnya.

\section{Langkah 2}

Setiap unit tersembunyi $(z j, j=1,2,3, \ldots, p)$ menjumlahkan delta input-nya (dari unitunit yang berada pad lapisan di atasnya).

Untuk menghitung informasi eror-nya kalikan dengan turunan dari fungsi aktivasinya.

Kemudian hitung koreksi bobot dan biasnya.

\section{Tahap Perubahan Bobot Dan Bias Langkah 1}

Setiap unit output (yk, $k=1,2,3, \ldots, m)$ dilakukan perubahan bobot dan bias $(j=1,2,3, \ldots, p)$.

Setiap unit tersembunyi $(z j, j=1,2,3, \ldots, p)$ dilakukan perubahan bobot dan bias.

\section{Langkah experimen menggunakan Algoritma:}

\section{Langkah 1}

Inisialisasi populasi

Tentukan nilai awal yang akan dijadikan gen-gen dengan nilai acak yang sudah ditentukan

\section{Langkah 2}

Evaluasi chromosome

\section{Langkah 3}

Seleksi chromosome

Proses seleksi dilakukan dengan cara membuat chromosome yang mempunyai fungsi_objektif tinggi yang kemungkinan besar terpilih atau yang mempunyai nilai probabilitas yang tinggi

\section{Langkah 4}

Crossover

Yaitu memilih secara acak satu posisi dalam chromosome induk kemudian saling menukar gen

\section{Langkah 5}

Mutasi
Yaitu dengan cara mengganti satu gen yang terpilih secara acak dengan suatu nilai baru yang didapat secara acak

\subsection{Evaluasi}

Berikutnya adalah mengevaluasi hasil penerapan model terhadap data set yang sudah dilakukan dengan melihat nilai Root Mean Square Error (RMSE) menggunakan persamaan (2). (Lee 1997)

Root Mean Square Error adalah penjumlahan kuadrat error atau selisih antara nilai aktual dengan nilai prediksi, kemudian membagi jumlah tersebut dengan banyaknya waktu data peramalan dan kemudian menarik akarnya. Jika nilai RMSE semakin kecil maka estimasi model atau variabel tersebut semakin baik.

$$
M S E=\sqrt{\frac{\sum_{(\text {Aktual-Prediksi })} 2}{n}}
$$

\section{HASIL DAN PEMBAHASAN}

\subsection{Proses Awal (Preprocessing)}

Proses awal yang dilakukan sebelum melakukan proses pengujian metode Backprogation Neural Network dan Genetic Algorithm adalah preprocessing data, dengan menggunakan persamaan pada rumus dibawah ini, yaitu:

$$
\begin{gathered}
x^{\prime}=\frac{x-\min \text { value }}{\max \text { value }-\min \text { value }} \\
\frac{25,297-4,175}{36,049-4,175}=0,66267
\end{gathered}
$$

Keterangan :

$\begin{array}{ll}25,297 & : \text { Data Awal } \\ 4,175 & : \text { Data Terendah } \\ 36,049 & : \text { Data Terbesar }\end{array}$


0,66267 : Hasil Normalisasi

Tabel 3.1: Normalisasi Data

\begin{tabular}{lll}
\hline BULAN & TAHUN & JUMLAH \\
\hline Januari & 2007 & 0,01672 \\
Februari & 2007 & 0,06319 \\
Maret & 2007 & 0,03815 \\
April & 2007 & 0,05321 \\
Mei & 2007 & 0,07432 \\
Juni & 2007 & 0,03018 \\
Juli & 2007 & 0,00273 \\
Agustus & 2007 & 0,02228 \\
September & 2007 & 0,08590 \\
Oktober & 2007 & 0,13911 \\
November & 2007 & 0,10394 \\
Desember & 2007 & 0,17739 \\
.... & $\ldots$. & $\ldots .$. \\
Desember & 2015 & 0,66267 \\
\hline
\end{tabular}

\subsection{Proses Penentuan Arsitektur Neural Network}

Berikutnya adalan Penentuan arsitektur Backpropagation Neural Network pada penelitian ini diperoleh model yang terbaik menggunakan Input Layer 4, dengan 9 Hidden Layer, Training Cycle 300, Learning Rate, 0,3 dan Momentum 0,2.

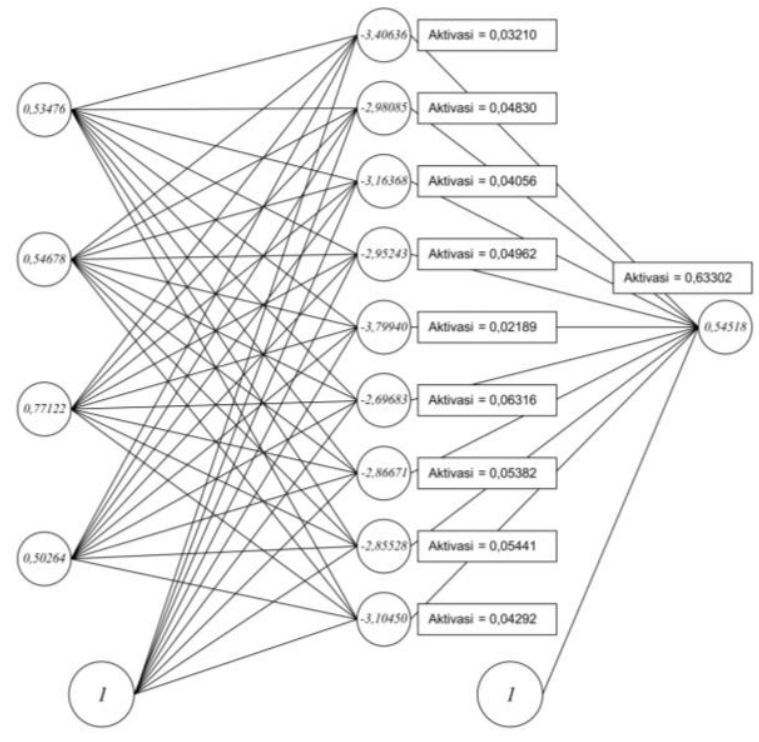

Gambar 3.1: Arsitektur Neural Network

\subsection{Evaluasi}

Hasil percobaan yang dilakukan menggunakan model arsitektur Backpropagation Neural Network sebelum di optimasi adalah sebagai berikut:

root_mean_squared_error

$0,120+/-0.036$ (mikro: 0,126 +/-0,000)

squared_error

$0,120+/-0,036$ (mikro: 0,126 +/-0,000)

Dari hasil experimen yang sudah dilakukan menggunakan Backpropagation Neural Network dan dioptimasi menggunakan Genetic Algoritm adalah sebagai berikut:

root_mean_squared_error

$0.115+/-0.029$ (mikro: $0.119+/-0.000$ )

squared_error

$0.014+/-0.008$ (mikro: $0.014+/-0.021$ ) 


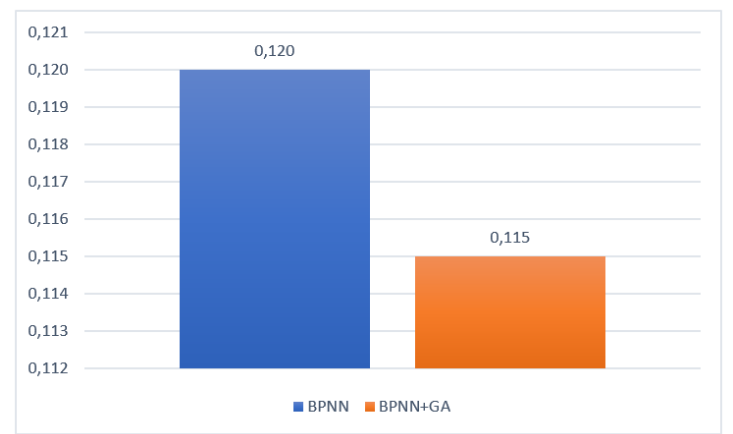

Gambar 3.2: Hasil RMSE Backprogation Neural Network \& Backprogation Neural Network + Genetic Algorithm

\section{KESIMPULAN}

Dapat ditarik kesimpulan dari experiment yang sudah dilakukan menggunakan Backprogation Neural Network menghasilkan Root Mean Sequare Error 0,120 setelah dioptimasi menggunakan Algoritma Genetika menghasilkan nilai Root Mean Sequare Error 0.115, penentuan bobot awal pada Backprogation Neural Network mempengaruhi model yang dihasilkan sehingga dapat meningkatkan kinerja Backprogation Neural Network lebih baik.

\section{REFERENCES}

Abhishek, Kumar, Abhay Kumar, Rajeev Ranjan, and Sarthak Kumar. 2012. "A Rainfall Prediction Model Using Artificial Neural Network." Proceedings - 2012 IEEE Control and System Graduate Research Colloquium, ICSGRC 2012, no. lcsgrc: 82-87. https://doi.org/10.1109/ICSGRC.2012 .6287140 .

Burse, Kavita, Manish Manoria, and Vishnu Pratap Singh Kirar. 2011. "Improved Back Propagation Algorithm to Avoid Local Minima in Multiplicative Neuron Model." Communications in Computer and Information Science 147 CCIS (12): 67-73. https://doi.org/10.1007/978-3642-20573-6_11.

Cui, Dapeng, and David Curry. 2005. 43
"Prediction in Marketing Using the Support Vector Machine." Marketing Science 24 (4): 595-615. https://doi.org/10.1287/mksc.1050.01 23.

Ding, Shifei, Chunyang Su, and Junzhao Yu. 2011. "An Optimizing BP Neural Network Algorithm Based on Genetic Algorithm." Artificial Intelligence Review 36 (2): 153-62. https://doi.org/10.1007/s10462-011 9208-z.

Habib, Md. 2013. "An Empirical Approach to Optimize Design of Backpropagation Neural Network Classifier for Textile Defect Inspection." British Journal of Mathematics \& Computer Science 3 (4): 617-34. https://doi.org/10.9734/bjmcs/2013/41 54.

Lee, Charles W. 1997. "Training Feedforward Neural Networks: An Algorithm Giving Improved Generalization." Neural Networks 10 (1): https://doi.org/10.1016/S08936080(96)00071-8.

Nawi, Nazri Mohd, Abdullah Khan, and Mohammad Zubair Rehman. 2013. "A New Back-Propagation Neural Network Optimized." Iccsa 2013, 413-26.

Nikelshpur, Dmitry, and Charles Tappert. 2013. "Using Particle Swarm Optimization to Pre-Train Artificial Neural Networks: Selecting Initial Training Weights for Feed-Forward Back-Propagation Neural Networks." Proceedings of Student-Faculty Research Day, 1-7.

Sexton, Randall S., and Naheel A. Sikander. 2001. "Data Mining Using a Genetic Algorithm-Trained Neural Network." International Journal of Intelligent Systems in Accounting, Finance \& Management 10 (4): 20110. https://doi.org/10.1002/isaf.205.

Siregar, Muhammad Noor Hasan. 2017. "Neural Network Analysis With Backpropogation In Predicting p-ISSN : 2502-5724; e-ISSN : 2541-5735 
Moh.Dasuki, Optimasi Nilai Bobot Algoritma Backpropagation Neural Network .. hlm 38 - 44

Human Development Index (HDI) Component by Regency/City In North Sumatera." IJISTECH (International Journal Of Information System \& Technology) $1 \quad$ (1): 22. https://doi.org/10.30645/ijistech.v1i1.3

Wanto, Anjar. 2018. "Penerapan Jaringan Saraf Tiruan Dalam Memprediksi Jumlah Kemiskinan Pada Kabupaten/Kota Di Provinsi Riau." Klik - Kumpulan Jurnal IImu Komputer $5 \quad$ (1): 61. https://doi.org/10.20527/klik.v5i1.129. 